Original Research Paper

\title{
Hazard and Risk in Iran
}

\author{
Maryam Marani Barzani and Khairulmaini Bin Osman Salleh \\ Department of Geography, University of Malaya Kuala Lumpur, Malaysia
}

\author{
Article history \\ Received: 10-01-2015 \\ Revised: 29-12-2015 \\ Accepted: 17-03-2017 \\ Corresponding author: \\ Maryam Marani Barzani \\ Department of Geography, \\ University of Malaya Kuala \\ Lumpur, Malaysia \\ Email: marani82@yahoo.com
}

\begin{abstract}
Hazard risk needs to consider vulnerability on human activities. Risk analysis of risk, human activities at spatial and temporal scales with existing classification of hazards and map hazard map. In this study hazard risk in urban areas could be useful through considering are used to model human activities such as population, land use and strategic situation in Zayandeh Rood Basin (Z.R.B), Iran. These human, activities are classified and combined with composite classified earthquake, desertification and dryness hazards maps to drive new spatially explicit five classes of composite map of the hazards and human activities. The obtained results show that there are significantly more people potentially at risk in Center and North of the basin at high classes of risk map. The proposed maps of human activities to hazards are mainly aimed at benefiting visualization and communication of hazards risk and can be valuable in all phases of the disaster management process where knowledge of human activities is relevant for decision making.
\end{abstract}

Keyword: Risk Map, Classification Hazards Map, Human Activities

\section{Introduction}

According to Freire and Aubrecht, (2012), risk has several definitions and different approaches exist for its analysis and mapping. Risk disaster is defined as a function of hazard probability and vulnerability, the latter resulting from a combination of exposure and ability to cope (UNDP, 2004; UNISDR, 2009). Risk assessment without human activities parameters is not characterized (Pelling, 2004). Human activities are very important in protecting humans from disaster. Freire and Aubrecht, (2012) believes that assessment and mapping of social vulnerability have traditionally been overlook in favor of hazard modeling studies.

According to Gibson (2010), risk is measured by several factors, including casualties (injuries, fatalities) and dollars (repair or replacement costs, loss of income or business). Risk mitigation involves minimising these factors, or the average annual rate, or the maximum expected loss. Risk zone refers to the human occupancy of hazard zone and human activities within the hazard area that would be potentially and directly affected by an event.

According to Merrett and Chen (2010), for many hazard occurrences, population exposure is arguably the greatest determinant of vulnerability and resulting losses and impacts. Therefore, the investigation of human activities as vital component of catastrophe impact modeling is one of the essential elements of effective risk analysis and emergency management.

Alcántara-Ayala (2002) studied natural hazards, vulnerability and prevention of natural disasters in developing countries. Rafiq and Blaschke (2012) created an integrated total risk assessment map. Mousavi et al. (2011) produced landslide susceptibility map. Moreover, Chandel Vishwa and Brar (2010) provided seismicity and vulnerability map in Himalayas.

Growing population in Z.R.B and growing the need of hazard management in the study area are the most important reasons for the application of risk analysis. In this study, risk hazard map will be provided for Z.R.B in Iran by using Arc map 9.3. Classification and composite methods were used to derive a composite hazard map of classified hazards map (Earthquake, desertification and dryness) and human activities. There were re-overly to form the human risk map.

The Z. R.B is located in the central part of Iran (Fig. 1). The area of the basin is about $42,000 \mathrm{~km}^{2}$. Figure 1 shows the situation of this basin on the map. There are more than one hazard in Z.R.B which are tectonic activities such as earthquake and desertification drought. On the other hand, human activities such as using land include land use, population and strategic situation especially in the largest city of the basin, Isfahan (Marani Barzani and Khairulmaini, 2013). 


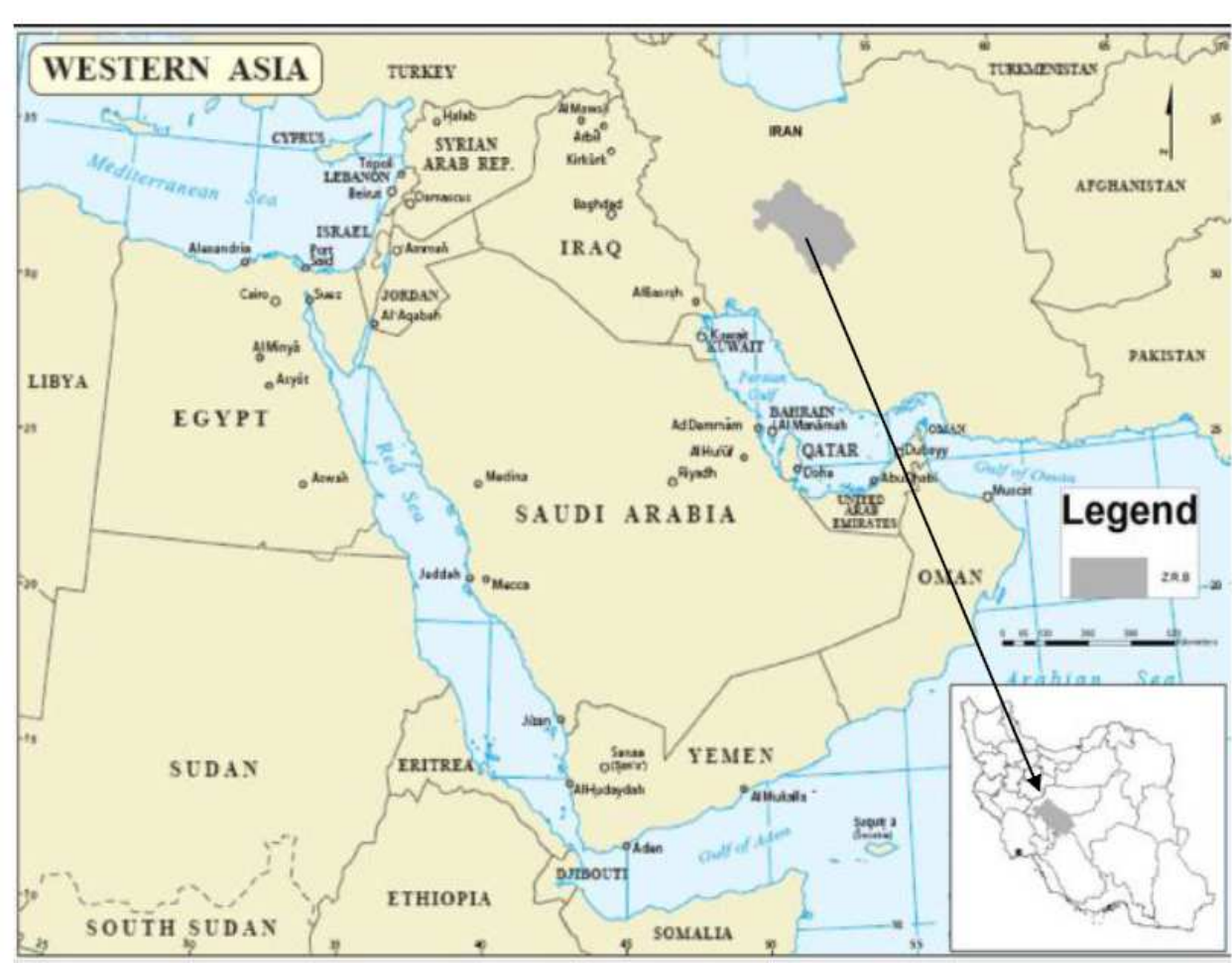

Fig. 1. Location of Z.R.B in Iran

\section{Materials and Methods}

Classified earthquake, desertification hazard maps and classified human activities maps are the datasets for mapping risk map. These datasets consist of a series of scoring and summing factors of the hazards and human activities parameters. These classification hazard maps were provided by scoring and weighted sum estimation. The parameters which have been considered for evaluating human activities include land use, population and strategic situation.

The following flowchart shows parameters of earthquake, desertification, dryness hazard and classified human activities in the study area. To produce the map, classified parameters by scoring were overlaid and then reclassified. The flowchart also shows the combination of hazards as composite classification hazard and density human activities maps for getting final map as risk map (Fig. 2).

Classified earthquake hazard map, classified desertification hazard map, composite hazard map and human activities parameters set are the materials used in this research. Classified earthquake hazard maps have been provided based on the hazards parameters which are magnitude, depth and fault and plate boundary for earthquake hazard map. Moreover, classified desertification hazard map has been provided by parameters such as soil characteristics, climate quality, elevation, land use, landform and geographical situation.

Three parameters of human activities including land use, strategic situation and population were selected for this paper. Figure 2 shows parameters of hazards and human activities which were considered for this research.

\section{Classified Human Activities Map}

In Z.R.B, human activities refer to land use, strategic situation and population. The majority of parameters concentrate on Center, West, South and West-North of the area. This study focuses on the three parameters of population, land use and strategic situation for evaluating distribution and risk map.

\section{Population}

In Z.R.B, the majority of the population reside in the Center of the basin. The high and very high population's classes reside in the city of Isfahan (Fig. 3).

\section{Land Use}

In Z.R.B, land use and land cover are selected as parameters for classified map. The classified land uses are forest, low agriculture, high agriculture, Bayer land and salinity land. The highest centers of agricultural land are located in the center of Z.R.B. There are a lot of plain lands in the city of Isfahan. 


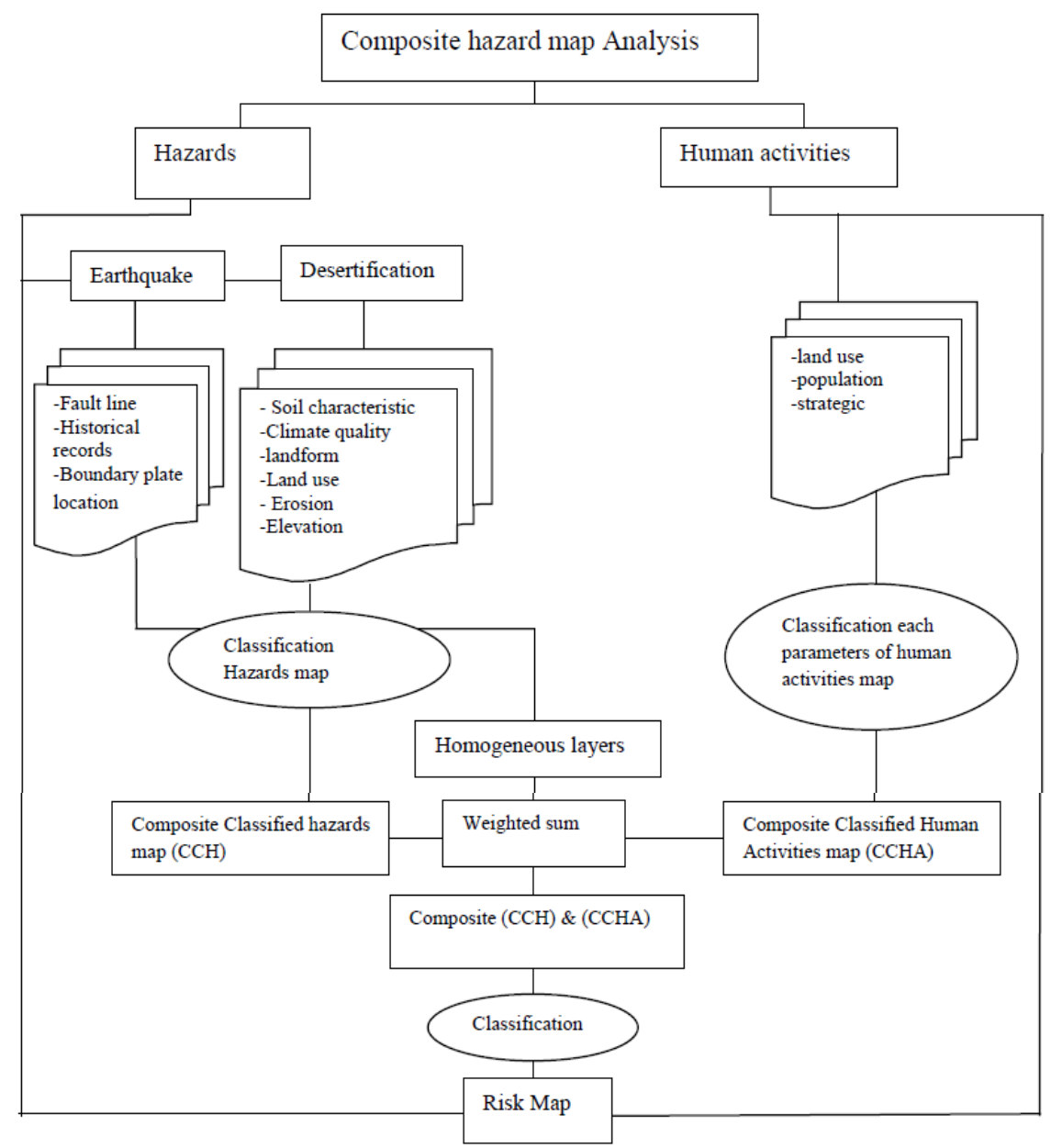

Fig. 2. Flowchart of Risk analysis Multi hazard
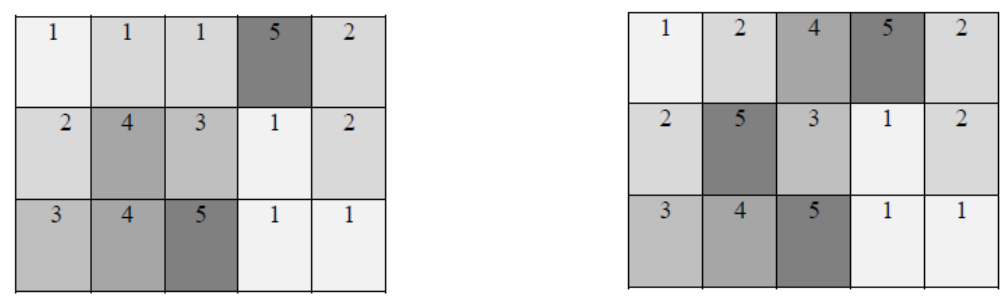

layer1 (Geomorphological hazard map) + $\quad+\quad$ layer 2 (Composite human activities map)

$=$

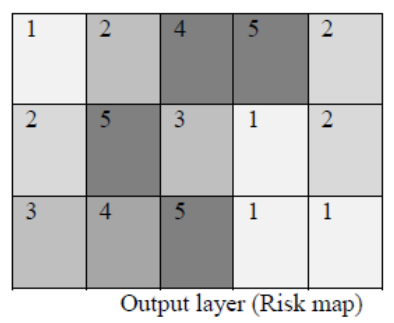

Fig. 3. Cell grid statistical of classes of hazards and human activities 


\section{Strategic Situation}

There are special strategic situations in the study area. The strategic parameters include dam, hospital, industrial centers and organizations. The strategic situation was selected as human activities parameters for classified risk map. The locations of strategic parameters are Center, West, North and South of the Z.R.B. In this research, the parameters were classified and shown by the strategic map (Fig. 3) by extraction of details from attribute sources. In this research, parameters of human activities were selected form attributes table and then were reclassified.

Combination of human activities parameters was done in GIS environment by classification method. The classified human activities map included five classes that the highest class was located on the center of Z.R.B. Moderate class covers majority of the basin (Fig. 3).

In this research, the final stage of methodology is providing risk map which is the combination of classified hazards map and classified human activities. In order to make risk map, the homogeneity of layers is important. The homogeneous layers of hazards and human activities are as input layers by cell statistic and weighted sum for classification risk map. Figure 3 shows scoring of each cell grid of the layers which are based on weighted sum.

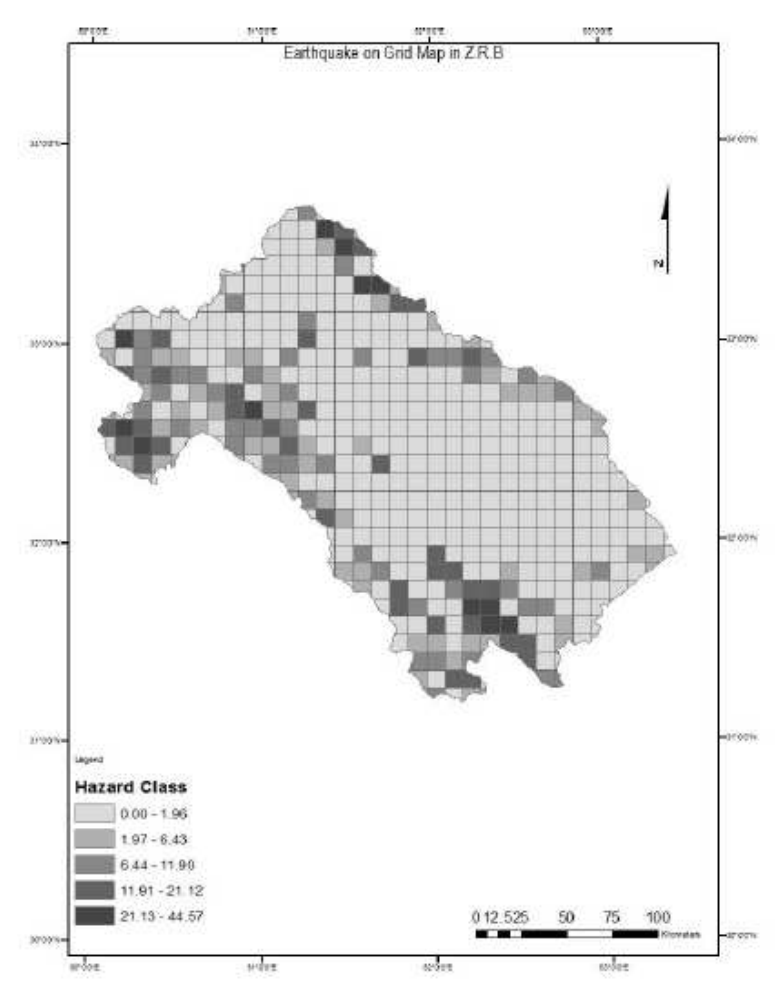

Figure 3 shows grid analysis based on weighted average. Each factor has measured in each grid based on unit. Then each factor classified in five classes and according to significant of the factors weighted average and reclassified. After this any hazard map classified and each grid was compared between the two hazard and human activities map.

In this research, the final stage of methodology is providing risk map which is the combination of classified hazards map and classified human activities. In order to make risk map, the homogeneity of layers is important. The homogeneous layers of hazards and human activities are as input layers by cell statistic and weighted sum for classification risk map. Figure 3 shows scoring of each cell grid of the layers which are based on weighted sum.

\section{Results and Discussion}

This study produced the composite risk map of Z.R.B which features earthquake and desertification as geomorphological hazards and composite human activities map. The modeled human activities represent maximum expected densities on typical human activities including industry, agricultural lands and settlements. Figure 4 quantified the total population potentially located in the city of Isfahan as the largest city in the basin.

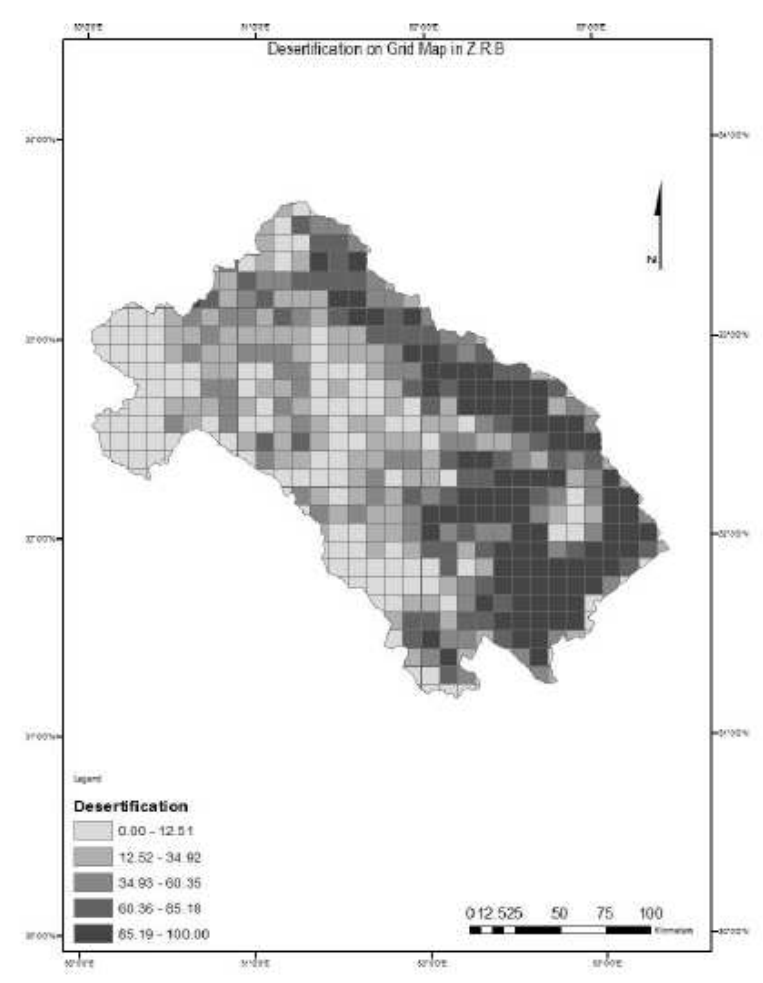



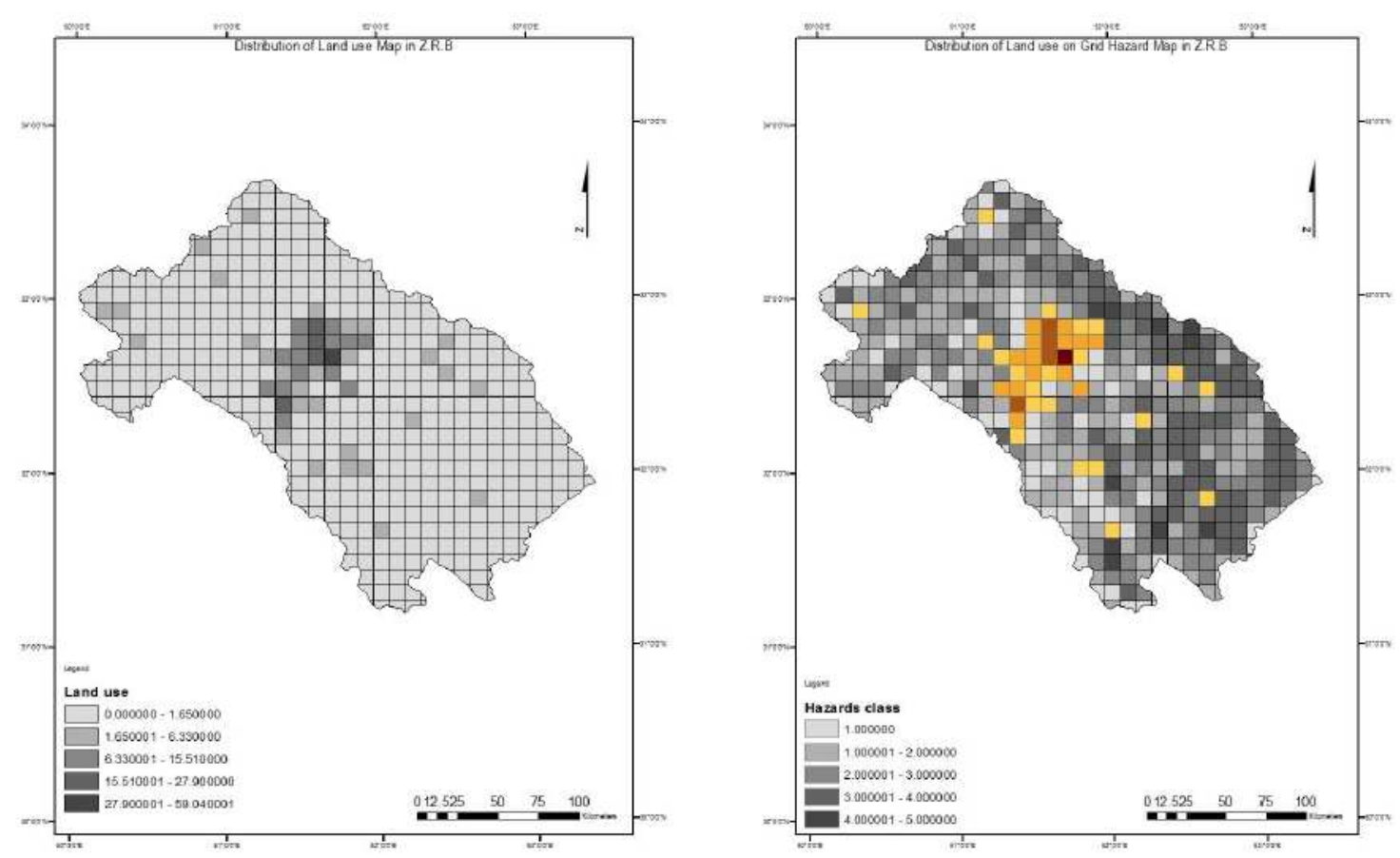

Fig. 4. Classification the hazards, Human activities and Risk map

Table 1. Distribution of hazard classes area and percentage in Z.R.B

\begin{tabular}{lccccrc}
\hline Class & Desertification & D\% & Earthquake & E\% & Land use & L\% \\
\hline 1 & 571.97 & 1.376 & 101.10 & 0.242 & 35.02 & 0.084 \\
2 & 2323.04 & 5.583 & 527.13 & 1.266 & 70.85 & 0.170 \\
3 & 3603.75 & 8.661 & 642.42 & 1.543 & 153.17 & 0.368 \\
4 & 4166.46 & 10.013 & 341.63 & 0.821 & 59.72 & 0.143 \\
5 & 9024.41 & 21.689 & & & 86.94 & 0.208 \\
Total & 19689.63 & 47.321 & 1612.28 & 3.874 & 405.70 & 0.975 \\
\hline
\end{tabular}

The result of this study is generating a risk map (Fig. 4). The risk hazard map shows five classes of hazards in Z.R.B. Density class shows the critical center in the area. Very high class is located in the North-North and East and Center of Z.R.B and very low class is located in the South and North- West part of Z.R.B. Distribution of other classes is extended to the whole area. Distribution of city on risk map shows that Isfahan as a large city and center of human activities is the hazard exposure. According to risk map of the hazards, human activities are at the risk of desertification from East and earthquake from Center and South in Z.R.B.

Table 1 shows hazards classification and area for each class of the hazards. High classes of desertification area is $9024.41 \mathrm{~km}^{2}$ that is $21.689 \%$ of whole basin area. The maturity of the hazard is located on North and East of Z.R.B. High classes of earthquake area is $341.63 \mathrm{~km}^{2}$ that is $0.821 \%$ of whole basin area. The maturity of earthquake is located on West-North and South of the basin. High classes of land use area is $86.94 \mathrm{~km}^{2}$ that is $0.208 \%$ of whole basin area.

\section{Conclusion}

An approach was developed that enable modeling and mapping of distribution and density of human activities and classification of multi-hazards map to advance analysis of hazards exposure and improve risk assessment. This research can be useful to be illustrated and apply it to large and multi-hazards areas.

Geomorphological processes are the main factors in the occurrence of geomorphological hazards. Classification and analyzing geomorphological hazard map would show the potential of hazards in the area. Composite hazard map is an important tool to identify the critical center of hazard and hazard management.

By analyzing the classification hazard, composite hazard map and risk map, the critical area can be found out. The identification of critical center of hazards would be important to prevent the hazard event and management planning. Defining where the risk hazard resides is one of the key questions for disaster mitigation and prevention policies. Geographic Information 
Systems (GIS) provide a powerful tool in managing and analyzing spatial data.

\section{Acknowledgment}

This work was supported by the University of Malaya and the data gathering was supported by Natural Resources Organization of Isfahan, Iran.

\section{Author's Contributions}

Maryam Marani Barzani: Make considerable contributions to conception and design and/or acquisition of data and/or Analysis and interpretation of data. Give final approval of the version to be submitted and any revised version.

Khairulmaini Bin Osman Salleh: Contribute in drafting the article or reviewing it critically for significant intellectual content.

\section{Ethics}

This article is original and contains unpublished material. The corresponding author confirms that all of the other authors have read and approved the manuscript and no ethical issues involved.

\section{Reference}

Alcántara-Ayala, I., 2002. Geomorphology, natural hazards, vulnerability and prevention of natural disasters in developing countries. Geomorphology, 47: 107-124.

DOI: 10.1016/S0169-555X(02)00083-1

Chandel Vishwa, B.S. and K.K. Brar, 2010. Seismicity and vulnerability in Himalayas: The case of Himachal Pradesh, India. Geomatics Nat. Hazards Risk, 1: 69-84. DOI: 10.1080/19475701003643441
Freire, S. and C. Aubrecht, 2012. Integrating population dynamics into mapping human exposure to seismic hazard. Nat. Hazards Earth Syst. Sci., 12: 3533-3543. DOI: $10.5194 /$ nhess-12-3533-2012

Gibson, G., 2010. Earthquake risk in Australia. Australian Planner.

Marani Barzani, M. and O.S. Khairulmaini, 2013. Desertification risk mapping of the Zayandeh Rood Basin in Iran. J. Earth Syst. Sci., 122: 1269-1282. DOI: $10.1007 / \mathrm{s} 12040-013-0348-1$

Merrett, H.C. and W.W. Chen, 2010. Applications of geographical information systems and remote sensing in natural disaster hazard assessment and mitigation in Taiwan. Geomatics Nat. Hazards Risk, 4: 145-163. DOI: 10.1080/19475705.2012.686064

Mousavi, S.Z., A. Kavian, K. Soleimani, S.R. Mousavi and A. Shirzadi, 2011. GIS-based spatial prediction of landslide susceptibility using logistic regression model. Geomatics Nat. Hazards Risk, 2: 33-50. DOI: 10.1080/19475705.2010.532975

Pelling, M., 2004. Visions of Risk: A Review of International Indicators of Disaster Risk and its Management. 1st Edn., UNDP Bureau for Crisis Prevention and Recovery, Geneva, pp: 56.

Rafiq, L. and T. Blaschke, 2012. Disaster risk and vulnerability in Pakistan at a district level. Geomatics Nat. Hazards Risk, 3: 324-341. DOI: $10.1080 / 19475705.2011 .626083$

UNDP, 2004. Reducing Disaster Risk - A challenge for development. A Global Report, United Nations Development Programme, New York, USA.

UNISDR, 2009. Terminology on disaster risk reduction. United Nations International Strategy for Disaster Reduction, Geneva, Switzerland. 